\title{
Optimal pricing and quality choice when investment in quality is irreversible
}

\section{Enrico Pennings}

IGIER - Bocconi University

\begin{abstract}
This paper examines the price and quality choice by a single product risk-neutral monopolist who can delay irreversible investments required for market entry. It is shown that the price and quality she chooses at entry increase with uncertainty about the size of future demand. As opposed to a myopic monopolist she provides a quality that is socially optimal, but the moment at which she invests will be later than socially optimal. In a Stackelberg leader-follower game the leader pre-commits immediately regardless of the level of market uncertainty and may opt for the lower quality good rather than the higher quality good when market uncertainty is high.
\end{abstract}

Keywords: Quality, Pricing, Irreversible Investment

JEL-code: D4, G31, L1.

\section{Correspondence to:}

Enrico Pennings, IGIER - Bocconi University, Via Salasco 3/5, 20136 Milano, Italy.

Tel: $\quad+39-02-58363300$

Fax: $\quad+39-02-58363302$

E-Mail: $\quad$ Enrico.Pennings@uni-bocconi.it

\section{Acknowledgment}

I would like to thank seminar participants at the Catholic University of Leuven and the EARIE 2001 Conference at Trinity College Dublin for helpful comments and suggestions. The first version of the paper was written when I was at Universitat Pompeu Fabra. 


\section{Introduction}

A stylized fact in empirical industrial organization is that investments in quality ${ }^{1}$ have been rather weak in industries with a low amount of sunk costs. Rashid (1988) for example reports that 'in reading about the fortunes of the English cloth industry, one is struck by the continued repetition of the complaints about quality.' High sunk costs industries, on the contrary, such as the pharmaceutical industry consistently provide goods of relatively high quality. Hence, irreversibility seems to play an important role in the choice of quality. Another empirical observation concerns the increase over time in quality and the number of firms when uncertainty about market demand is high. A pioneering firm is usually small (Lowe and Atkins, 1994) and second movers enter when market demand develops favorably. The sequence of Internet browsers is a good example. Mosaic, the first Internet browser was very limited and of poor quality. The subsequent products by Netscape and Microsoft were introduced when the market took off and offered a much higher quality.

However, the theory of irreversible investments (see Dixit and Pindyck, 1994, for an excellent survey) has hitherto focused on undertaking a fixed cost investment with an uncertain payoff, which means that the firm has no choice in deciding on the quality of installed capital and output. Not only the choice of quality has not been examined in the literature of the so-called 'real options', also other important strategic variables that a firm has at its disposal such as the price of its products are typically neglected. In the nineties the literature was extended by strategic interaction between two firms with the opportunity to invest (Smets, 1991; Lambrecht and Perraudin, 1997; Kulatilaka and Perotti, 1998; Weeds, 2000), but the payoffs they receive when they

\footnotetext{
${ }^{1}$ We refer to quality as any product attribute that makes a consumer decide to buy a particular product, the competitor's product or none, e.g. service, product life, product features, etc.
} 
invest depend only on the timing and order of investment and are independent of price and quality choice.

In the theory of the firm quality choice in a vertically differentiated industry is a topical concern since the seminal contribution by Spence (1975) who showed that a monopolist produces too high or too low a quality as compared to the social optimum. Subsequently, models of oligopolistic competition under quality differentiation (Gabszewicz and Thisse, 1979; Shaked and Sutton, 1982) show that firms maximize profits by maximal product differentiation as to relax price competition. Recent developments that are related to this paper are Lehmann-Grube (1997) who shows that for every convex fixed cost function of quality improvement the higher quality firm earns the higher profits, and Aoki and Prusa (1996) who demonstrate that the timing of quality choice affects the levels of quality chosen by firms.

This paper extends the real option literature as well as the literature on vertical product differentiation by examining quality choice and entry timing when future market demand is uncertain. First, it derives closed form solutions for a risk neutral monopolist's optimal amount of irreversible investment in capital, its quality choice, its price setting, and its entry timing given a convex and increasing relation between quality of the output and investment cost. Extending the basic model of quality choice by Spence (1975) into a dynamic one where the monopolist chooses its entry timing under uncertainty about the market size, we show that the monopolist produces a quality equal to the one chosen by a social planner, whereas in the static version of the model the monopolist would produce a too low quality from the social point of view. However, the monopolist postpones investment over a period that is larger than socially optimal. Moreover it is demonstrated that the optimal quality is increasing in market uncertainty, which gives an explanation of why quality choice is low when uncertainty 
is low or when the investment entails small sunk cost, such as in the aforementioned English cloth industry.

Though we are able to derive analytical results for all the decision parameters set by the monopolist, the model becomes unsolvable in the case of duopoly. Numerical results give some interesting insights into the outcome of the stochastic and dynamic Stackelberg duopoly game. Since the high quality producer reaps more profits than the low quality producer in the standard duopoly models of quality choice, it seems intuitive that the leader produces the higher quality good (Tirole, 1988). High quality production, however, entails a larger sunk cost investment than low quality production. Therefore the second mover, producing a lower quality and having a lower option value of waiting, immediately enters the market after the first mover. So the high quality first entrant will not benefit from a period in which it reaps monopoly benefits.

On the contrary, if the first entrant decides to produce the lower quality, the high quality firm facing a large irreversible investment postpones investment until a relatively large market size is reached, thereby providing the low quality firm with a large period of monopoly benefits. We show that in equilibrium the leader will indeed earn higher profits by supplying the low quality product when uncertainty is relatively high. This result is in line with the aforementioned example of sequential entry of Internet browsers, but contradicts the theoretical results found by Aoki and Prusa (1996) and Lehmann-Grube (1997). Aoki and Prusa (1996) argue that in the equilibrium of the sequential choice game, the leader will supply the high quality product. Lehmann-Grube (1997) shows in a static model that for every convex fixed-cost function of quality improvement, the high-quality firm earns the higher profits.

Another result in the Stackelberg duopoly game which is contradictory to existing theoretical results is the optimality of immediate investment by the leader, 
regardless of the level of market uncertainty, which means that there is never value in waiting for the leader. The reason is that in existing models of irreversible investment payoffs move exogenous and are independent of the choice of strategic variables ${ }^{2}$.

This paper is organized as follows. In section 2 we will derive the model for the optimal quality, price and critical market size of a monopolist facing an uncertain market size and able to postpone market entry. Section 3 analyzes the social planner's choice of quality, price and market size and discusses differences with section 2 . In section 4 we derive the firm profits and the equilibrium outcomes in a Stackelberg duopoly game. In the conclusion we discuss the limitations of the model and propose an investment grant as to increase social welfare.

\section{Monopolist's choice}

The basic idea in the theory of investment under uncertainty is that the firm invests when the value of the investment project, $\mathrm{V}$, exceeds the cost of investment, I, by the value of waiting to invest (McDonald and Siegel, 1986). Writing V as $\pi \cdot N$, we can think of $\pi$ as the profit per consumer and $\mathrm{N}$ as the number of consumers. Now let $\pi$ and $\mathrm{I}$ be functions of quality, denoted by s with $\pi(0)=0$, and $\pi(\infty)<\infty$. Furthermore it is assumed that $\pi_{\mathrm{s}}, \pi_{\mathrm{ss}}, \mathrm{I}_{\mathrm{s}}$, and $\mathrm{I}_{\mathrm{ss}}$, the first and second order derivatives of $\pi$ and I respectively, are positive, and that $\mathrm{N}$ follows a geometric Brownian motion. The risk-neutral firm chooses quality and critical market size so as to maximize expected profits. The first order condition with respect to $\mathrm{s}$ is $\pi_{\mathrm{s}} \cdot \mathrm{N}=\mathrm{I}_{\mathrm{s}}$, while the critical value of profits at which it is optimal to invest, $\pi \cdot \hat{\mathrm{N}}$, is characterized by $\pi \cdot \hat{\mathrm{N}}=\xi \cdot I$, where $\xi$, with $\xi>1$, is a markup

\footnotetext{
${ }^{2}$ It should be noted that the generality of the results do not depend on the expected growth rate of consumer demand, but only on the existence of uncertainty about future market demand.
} 
parameter that is increasing with uncertainty under normal conditions (Dixit and Pindyck, 1994). Combining both equations it must be true that $\varepsilon_{\mathrm{I}}=\xi \cdot \varepsilon_{\pi}$, where $\varepsilon_{\mathrm{I}}$ and $\varepsilon_{\pi}$ denote the elasticity of the investment cost and the project value per consumer, respectively, with respect to quality. Suppose that $\varepsilon_{\mathrm{I}}$ is constant, whereas the assumptions on the shape of $\pi$ imply that $\varepsilon_{\pi}$ is a decreasing function of s. Hence, we find as a general result for quality choice when investment is irreversible that an increase in uncertainty, represented by an increase in $\xi$, must lead to higher quality.

The intuition behind this result is that investing under a larger pool of consumers not only yields higher revenue but also higher marginal revenue. Since the cost of investment in quality is convex and increasing, the quality at which marginal revenue equals marginal cost increases. The theory on investment under uncertainty predicts a positive relation between uncertainty and the market size at which market entry is optimal. Therefore, higher uncertainty about the market size has a positive impact on quality choice. More generally speaking, the ability to postpone investment enables the monopolist to enter into a larger market, producing a higher quality than it would in a smaller market.

In the following we extend the quality choice with the simultaneous choice of product price under the assumption that the monopolist can only choose one quality of a good that will be new into a market that fluctuates randomly with respect to its size. Though she cannot price discriminate between consumers, she can determine the moment at which she enters the market.

\subsection{Demand function}

Consumers, differing from each other with respect to their taste of quality, may purchase either a single unit of a newly produced good or none at all. Following the 
basic models of quality choice (e.g. Tirole, 1988) we describe the consumer's preferences as

$$
U(p, s)=\theta s-p
$$

if the consumer buys one unit of a good with quality $s$ at price $p$ and $U=0$ otherwise. $\theta$ is a taste parameter that varies over consumers and is assumed to be continuously and uniformly distributed over the interval $[0,1]$. The demand for the good is equal to the number of consumers with taste parameter $\theta$ such that $\theta s \geq p$. Hence, the demand function is given by

$$
q(p, s)=N[1-p / s]
$$

where $\mathrm{N}$ represents the total number of consumers. We assume that $\mathrm{N}$ follows a geometric Brownian motion with drift $\mu$ and standard deviation $\sigma$. So $\mathrm{N}$ is distributed according to a lognormal distribution at each instant and $\mathrm{N}$ has independent increments.

\subsection{Cost function}

We adopt the cost function from Ronnen $(1991)^{3}$; i.e. we assume that marginal cost, denoted by c, is constant and that providing a quality of s requires a fixed development cost of $I(s)$ which is increasing in s, as is its marginal development cost. Moreover it is assumed that the development costs are a sunk cost investment.

\subsection{Profit function}

The monopolist can enter the market at any instant by undertaking the investment and will receive monopoly profits from that moment on. Let $\mathrm{T}$ denote the moment of market

\footnotetext{
${ }^{3}$ Related studies such as Motta (1993), Boom (1995), Aoki and Prusa (1996), and Lehmann-Grube (1997) also assume that marginal cost is independent of quality; see Lehmann-Grube (1997) for a detailed motivation.
} 
entry. Furthermore let $r$ represent the appropriate discount rate (with $r>\mu$ as to ensure finite profits), and let subscript $\mathrm{m}$ refer to the choice variables of the monopolist. Then expected profits can be written as

$$
E\left[\left(p_{m}-c\right) \int_{T}^{\infty} \exp (-r t) N(t)\left[1-p_{m} / s_{m}\right] d t\right]-\exp (-r T) I\left(s_{m}\right)
$$

The equation can be rewritten as

$$
E\left[\exp (-r T)\left\{\left(p_{m}-c\right)\left[1-p_{m} / s_{m}\right] N(T) /(r-\mu)-I\left(s_{m}\right)\right\}\right] .
$$

Let the market size at which the monopolist decides to enter the market, $N(T)$, be denoted by $N_{m}$. Following the theory on first passage time of Brownian motion (e.g. Dixit and Pindyck, 1994, p315-p316), we can finally write the profit equation as

$$
\left(N / N_{m}\right)^{\beta}\left\{\left(p_{m}-c\right)\left[1-p_{m} / s_{m}\right] N_{m} /(r-\mu)-I\left(s_{m}\right)\right\} .
$$

where $\beta=-\left(\mu-\frac{1}{2} \sigma^{2}\right) / \sigma^{2}+\sqrt{\left(\left(\mu-\frac{1}{2} \sigma^{2}\right) / \sigma^{2}\right)^{2}+2 r / \sigma^{2}}$ (e.g. Dixit and Pindyck, 1994, p142) with $\beta>1$.

\subsection{Optimal behavior of a monopolist}

The risk-neutral monopolist maximizes expected profits with respect to price, quality, and the market size at which to enter. The first order condition with respect to $p_{m}, s_{m}$, and $N_{m}$ are

$$
\begin{gathered}
\hat{p}_{m}=\frac{1}{2}\left(\hat{s}_{m}+c\right), \\
\frac{\hat{N}_{m} \hat{p}_{m}\left(\hat{p}_{m}-c\right)}{(r-\mu) \hat{s}_{m}^{2}}=\frac{\partial I}{\partial s}, \\
\left(\hat{p}_{m}-c\right)\left[1-\hat{p}_{m} / \hat{s}_{m}\right] \hat{N}_{m}=(r-\mu) \xi I\left(\hat{s}_{m}\right),
\end{gathered}
$$

respectively, where $\xi=\beta /(\beta-1)$, with $\xi>1$ denoting the parameter that represents the required markup over the cost of investment. Under normal conditions the markup 
parameter is increasing in uncertainty. Given an investment cost function $I(s)=\alpha s^{\gamma}$, and solving for $\hat{p}_{m}, \hat{s}_{m}$, and $\hat{N}_{m}$, we have

$$
\begin{gathered}
\hat{p}_{m}=c \frac{\gamma}{\gamma-\xi}, \\
\hat{s}_{m}=c\left(\frac{\gamma+\xi}{\gamma-\xi}\right), \\
\hat{N}_{m}=\frac{\alpha(r-\mu)\left(\gamma^{2}-\xi^{2}\right) c^{\gamma-1}}{\xi}\left(\frac{\gamma+\xi}{\gamma-\xi}\right)^{\gamma},
\end{gathered}
$$

with $\gamma>\xi$ and $\alpha>0$ being necessary conditions to ensure a positive price, quality, and critical market size. From equation (9) and (10) it becomes clear that optimal price, quality, and quality per unit price are increasing in the markup (increasing in uncertainty). Since demand per consumer depends on the ratio of quality and price, demand per consumer is also increasing in uncertainty.

A static treatment of optimal quality and price is surprisingly more complicated since solving the first order equations gives price as $\hat{p}_{m}=\frac{1}{2}\left(\hat{s}_{m}+c\right)$, but quality is only implicitly given by the equation $N \hat{s}_{m}^{2}-4 \alpha(r-\mu) \gamma s_{m}^{\gamma+1}=N c^{2}$.

\section{Social planner's choice}

A social planner chooses price, quality, and entry timing so as to maximize social benefits, which consist of the difference between the expected net present value of consumer surplus and production cost.

\subsection{Social benefits}

Let $p_{g}, s_{g}$, and $N_{g}$ denote the price, quality and market size at entry in the social planner's model. Expected social benefits can be written as 


$$
\left(N / N_{g}\right)^{\beta}\left(N_{g}\left\{\int_{p_{g}}^{s_{g}}\left[1-x / s_{g}\right] d x+\left(p_{g}-c\right)\left[1-p_{g} / s_{g}\right]\right\} /(r-\mu)-I\left(s_{g}\right)\right)
$$

which equal

$$
\left(N / N_{g}\right)^{\beta}\left(N_{g}\left\{\frac{1}{2} s_{g}-c+\left(p_{g} c-\frac{1}{2} p_{g}^{2}\right) / s_{g}\right\} /(r-\mu)-I\left(s_{g}\right)\right)
$$

\subsection{Optimal behavior of social planner}

Maximizing (13) with respect to $p_{g}$ gives the first order condition

$$
\hat{p}_{g}=c
$$

which is the familiar equality between price and marginal cost. With the investment cost function of section 2.4 , the first order condition with respect to $s_{g}$ reads

$$
\hat{N}_{g}\left\{\frac{1}{2}-\left(\hat{p}_{g} c-\frac{1}{2} \hat{p}_{g}^{2}\right) / \hat{s}_{g}^{2}\right\}=(r-\mu) \gamma \alpha \hat{s}_{g}^{\gamma-1},
$$

while the first order condition with respect to $N_{g}$ is

$$
\hat{N}_{g}\left\{\frac{1}{2} \hat{s}_{g}-c+\left(\hat{p}_{g} c-\frac{1}{2} \hat{p}_{g}^{2}\right) / \hat{s}_{g}\right\}=(r-\mu) \xi \alpha \hat{s}_{g}^{\gamma}
$$

Substituting (14) in (15) and (16), and solving (15) and (16) for $\hat{s}_{g}$ and $\hat{N}_{g}$, we have

$$
\begin{gathered}
\hat{s}_{g}=c\left(\frac{\gamma+\xi}{\gamma-\xi}\right) \\
\hat{N}_{g}=\frac{\alpha(r-\mu)\left(\gamma^{2}-\xi^{2}\right) c^{\gamma-1}}{2 \xi}\left(\frac{\gamma+\xi}{\gamma-\xi}\right)^{\gamma} .
\end{gathered}
$$

Comparing the social planner's choice with the one by the monopolist we find that the social optimal quality exactly equals the monopolist's quality choice. However, whereas the monopolist charges a markup over its marginal cost, the social planner sets price equal to marginal cost. Most interestingly, the market size at which the social planner 
would enter is exactly half of the market size at which the monopolist would enter. ${ }^{4}$ Hence, the monopolist's ability to postpone irreversible investments in quality does not lead to 'overprovision' or 'underprovision' of the actual quality of the good, but to an amount of investment in quality that is less than socially optimal.

In the static version of the model, the social planner obviously sets price equal to marginal cost, whereas optimal quality is implicitly given by the equation $N \hat{s}_{g}^{2}-2 \alpha(r-\mu) \gamma s_{g}^{\gamma+1}=N c^{2}$. Comparing this result with the myopic monopolist choice noted at the end of the previous section, we find that a static treatment of the model implies underprovision of quality. ${ }^{5}$ Admittedly, the statement that there is no underprovision of quality in the dynamic model is only correct when the initial market size is smaller than $N_{g}$. When $N>N_{g}$, the social planner would invest immediately and the static model for the social planner applies. In the static framework quality increases with market size. ${ }^{6}$ Hence, the social planner would choose a quality larger than $\hat{s}_{g}$ when $N>N_{g}$.

\footnotetext{
${ }^{4}$ Note that the difference between the critical values at which to invest depends on the discrepancy between social benefits and monopoly profits (i.e. the sum of consumer surplus and the deadweight loss in the monopoly model) at the optimal prices and qualities. Since demand is linear in the model examined here, monopoly profits exactly equal the sum of consumer surplus and deadweight loss at the optimal choices of prices and qualities.

${ }^{5}$ The simplest way to 'prove' this is to think of a social planner behaving as a monopolist but having exactly half of the monopolist's cost of quality. Since marginal revenue of quality is unaffected, the monopolist provides a higher quality when cost of quality decreases. Therefore, the social planner supplies a higher quality than the monopolist does.

${ }^{6}$ This can be seen by dividing the 'static' equations for $\hat{s}_{g}$ by N. Then the quality choice is similar to the case of a unit market size with a cost that is inversely related to N. So applying the same argument as in footnote 3 , quality increases with $\mathrm{N}$.
} 


\section{Duopoly profits}

The vertical product differentiation model with two goods has been studied extensively in the literature (e.g. Tirole, 1988). The general result of these models is that firms offer distinct qualities as to soften competition in prices. The usual set-up of the model involves a two-stage game in which firms fix qualities in the first stage and choose prices in the second stage ${ }^{7}$. As in the previous sections and contrary to the usual set-up we consider a continuous-time model where the decision on when and how much to invest in quality are endogenously determined. As in Smets (1991), firms may deviate with respect to their timing of entry (i.e. timing of investment). Therefore the model allows for a first mover advantage in the form of monopoly profits in addition to the value of pre-commitment to investment in a certain quality ${ }^{8}$.

We examine a Stackelberg game where the leader and follower are exogenously assigned ${ }^{9}$. In the Stackelberg equilibrium the leader either offers the lower quality good or the higher quality good. She decides on the price until the follower comes into the market $\left(p_{m}^{L}\right)$, the price she charges when both firms compete in duopoly $\left(p_{d}^{L}\right)$, the

\footnotetext{
${ }^{7}$ Motta (1993) numerically calculates the equilibrium values of quality and price in duopoly games of vertical product differentiation.

${ }^{8}$ The trade-off between pre-commitment to the strategic variables in a first stage and flexibility to alter the strategic parameters in a second stage has been examined in Spencer and Brander (1992) and Maggi (1996).

${ }^{9}$ Scherer (1980) suggests that Stackelberg outcomes are likely when firms are of different sizes or dispose of different technologies. Sadanand and Sadanand (1996) give a formal proof that Stackelberg equilibria arise when firms differ with respect to their size. In a two-stage model of vertical product differentiation Aoki and Prusa (1996) show that aggregate firm profits are higher under sequential choice of quality so that firms would prefer to compete in a sequential move (Stackelberg) game.
} 
investment in quality $\left(s^{L}\right)$, and finally the critical market size at which she decides to enter $\left(N^{L}\right)$. The follower sets price $\left(p^{F}\right)$, quality $\left(s^{F}\right)$ and the critical market size at which he enters the market $\left(N^{F}>N^{L}\right)$. Leader profits consist of the present value of monopoly profits before the follower enters, the present value of duopoly profits she reaps afterwards, minus the present value of the cost of entry. Let $D_{m}^{L}$ denote the demand faced by the leader acting in monopoly. Furthermore let $D_{d}^{L}$ and $D_{d}^{F}$ represent demand for the leader and follower in duopoly, respectively. We have (e.g. Tirole, 1988) $\quad D_{m}^{L}=1-p_{m}^{L} / s^{L}, \quad D_{d}^{L}=1-\left(p_{d}^{L}-p_{d}^{F}\right) /\left(s^{L}-s^{F}\right) \quad$ if $\quad s^{F}<s^{L}, \quad$ and

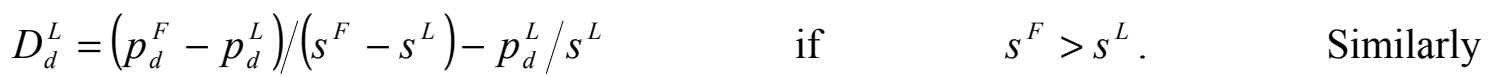
$D_{d}^{F}=\left(p_{d}^{L}-p_{d}^{F}\right) /\left(s^{L}-s^{F}\right)-p_{d}^{F} / s^{F}$ if $s^{F}<s^{L}$, and $D_{d}^{F}=1-\left(p_{d}^{F}-p_{d}^{L}\right)\left(s^{F}-s^{L}\right)$ if $s^{F}>s^{L}$. Now, the leader's expected profits, $\pi^{L}$, can be expressed as

$$
\left(\frac{N}{N^{F}}\right)^{\beta} \frac{N^{F}\left(p_{d}^{L}-c\right) D_{d}^{L}}{r-\mu}+\left[\left(\frac{N}{N^{L}}\right)^{\beta}-\left(\frac{N}{N^{F}}\right)^{\beta}\right] \frac{N^{L}\left(p_{m}^{L}-c\right) D_{m}^{L}}{r-\mu}-\left(\frac{N}{N^{L}}\right)^{\beta} \alpha\left(s^{L}\right)^{\gamma}
$$

The follower maximizes his expected profits, $\pi^{F}$, given by

$$
\left(\frac{N}{N^{F}}\right)^{\beta}\left[\frac{N^{F}\left(p^{F}-c\right) D^{F}}{r-\mu}-\alpha\left(s^{F}\right)^{\gamma}\right]
$$

with respect to price, quality choice, and entry timing. This maximization yields reaction functions $p^{F}\left(p_{d}^{L}, s^{L}, N^{L}\right), s_{2}^{F}\left(p^{L}, s^{L}, N^{L}\right)$ and $N^{F}\left(p_{d}^{L}, s^{L}, N^{L}\right)$. Given these reaction functions the leader maximizes equation (19) with respect to $p_{m}^{L}, p_{d}^{L}, s^{L}$, and $N^{L}$. 
Table 1 shows the equilibrium outcome of the Stackelberg duopoly game. In the static model (which is equivalent to the case where $\beta$ approaches infinity) the follower can only make a positive profit by providing the lower quality good. In the dynamic model with non-negative uncertainty the flexibility value is low for both firms. The equilibrium outcome is provision of the higher quality good by the leader and of the lower quality good by the follower. As uncertainty increases, uncertainty provides the follower with an incentive to postpone investment $\left(\hat{N}_{F}>N\right)$ and to introduce a higher quality product in a larger market. The leader chooses to invest immediately regardless of the level of uncertainty so her value of pre-commitment always exceeds her value of flexibility. While the follower benefits from higher uncertainty through the option value of waiting to invest, the leader reaps monopoly profits until the follower enters. The table shows that the higher the uncertainty in the market, the higher the differentiation is in quality. The reason is that higher differentiation in quality increases the follower's profit per consumer and hence its value of waiting, whereas more delay in entry by the follower leads to an increase in the leader's monopoly profits that is larger than its decrease in duopoly profits. This result contradicts Smets (1991) who showed that the leader's critical value at which to invest does depend on uncertainty. The intuition is that in our model the firm strategically sets prices and quality as to deter entry by the follower whereas in his model the firm can only choose the timing of entry.

Moreover the table shows that uncertainty about market demand has a high impact on the equilibrium outcome. In contrast to Aoki and Prusa (1996) we find that under high uncertainty the leader will supply the lower quality product. Contrary to Lehmann-Grube (1997) the firm that provides the higher quality does not earn the higher profit when uncertainty is relatively high. 


\section{Conclusion}

In this paper we showed that uncertainty has a positive impact on the quality choice of a monopolist when investment in quality is irreversible. In a Stackelberg leader-follower game we showed that the leader may opt for the lower quality good. Sequential entry, with quality increasing over time as demand turns out favorable, is the equilibrium outcome when uncertainty is relatively high. Though we think that considering irreversibility, uncertainty and dynamics in a model of vertical product differentiation is a significant move beyond the traditional static model, the analysis neglects several issues that turn up in dynamic models, such as learning from the pioneering firm, brand loyalty, switching costs, network effects, and sequential or continuous quality upgrading by the pioneering firm. We leave these topics for further research.

Finally, a note on policy advice with respect to the findings. Minimum quality standards have often been proposed as a means to increase welfare. However, the outcome of the monopoly model with stochastic demand limits the necessity of a minimum quality standard, but calls for investment subsidies to raise welfare. In the monopoly model a grant of $50 \%$ of the investment cost would result into an amount of investment that is optimal from the social point of view. Without investment subsidies there would not be underprovision of quality, as predicted in a static model, but underprovision of investment in quality. With respect to the duopoly model, the equilibrium outcome predicts a long period of sustained monopoly profits for the leader when uncertainty is relatively high. The primary reason for this result is the high sunk cost investment by the follower. As in the monopoly model, an investment grant would reduce the follower's value of waiting, and hence increase competition and welfare. 


\section{References}

Aoki, R. and T.J. Prusa (1996), Sequential versus Simultaneous Choice with Endogenous Quality, International Journal of Industrial Organization 15, 103-121. Boom, A. (1995), Asymmetric International Minimum Quality Standards and Vertical Differentiation, Journal of Industrial Economics 43, 101-119.

Dixit, A.K. and R.S Pindyck (1994), Investment under Uncertainty, Princeton University Press, Princeton, NJ.

Gabszewicz, J. and J.-F. Thisse (1979), Price Competition, Quality and Income Distribution, Journal of Economic Theory 20, 349-359.

Kulatilaka, N. and E. Perotti, (1998), Strategic Growth Options, Management Science 44, 1021-1031.

Lambrecht, B. and W. Perraudin (1997), Real Options and Preemption, Working Paper, University of Cambridge.

Lehmann-Grube (1997), Strategic Choice of Quality when Quality is Costly: The Persistence of the High-Quality Advantage, Rand Journal of Economics 28, 372384.

Lowe, J. and M.H. Atkinson (1994), Smallest Companies Tending to Be the Most Pioneering, International Journal of the Economics of Business 1, 405-422.

Maggi, G. (1996), Endogenous Leadership in a New Market, Rand Journal of Economics 27, 641-659.

McDonald, R. and D. Siegel (1986), The Value of Waiting to Invest, Quarterly Journal of Economics 101, 707-728.

Motta M. (1993), Endogenous Quality Choice: Price vs. Quantity Competition, Journal of Industrial Economics 41, 113-131. 
Rashid, S. (1988), Quality in Contestable Markets: A Historical Problem?, Quarterly Journal of Economics 102, 245-249.

Ronnen, U. (1991), Minimum Quality Standards, Fixed Costs, and Competition, Rand Journal of Economics 22, 490-504.

Sadanand, A. and V. Sadanand (1996), Firm Scale and Endogenous Timing of Entry: a Choice between Commitment and Flexibility, Journal of Economic Theory 70, 516-530.

Scherer, F. (1980), Industrial Market Structure and Economic Performance, Rand McNally, Chicago.

Shaked, A. and J. Sutton (1982), Relaxing Price Competition through Product Differentiation, Review of Economic Studies 49, 3-13.

Smets, F. (1991), Exporting versus Foreign Direct Investment: The Effect of Uncertainty, Irreversibilities and Strategic Interactions, Working Paper, Yale University.

Spence, M. (1975), Monopoly, Quality and Regulation, Bell Journal of Economics 6, 417-429.

Spencer, B. and J. Brander (1992), Pre-commitment and Flexibility: Applications to Oligopoly Theory, European Economic Review 36, 1601-1626.

Tirole, J. (1988), The Theory of Industrial Organization, MIT Press, Cambridge, MA.

Weeds, H. (2000), Strategic Delay in a Real Options Model of Competition, Working Paper, University of Warwick. 


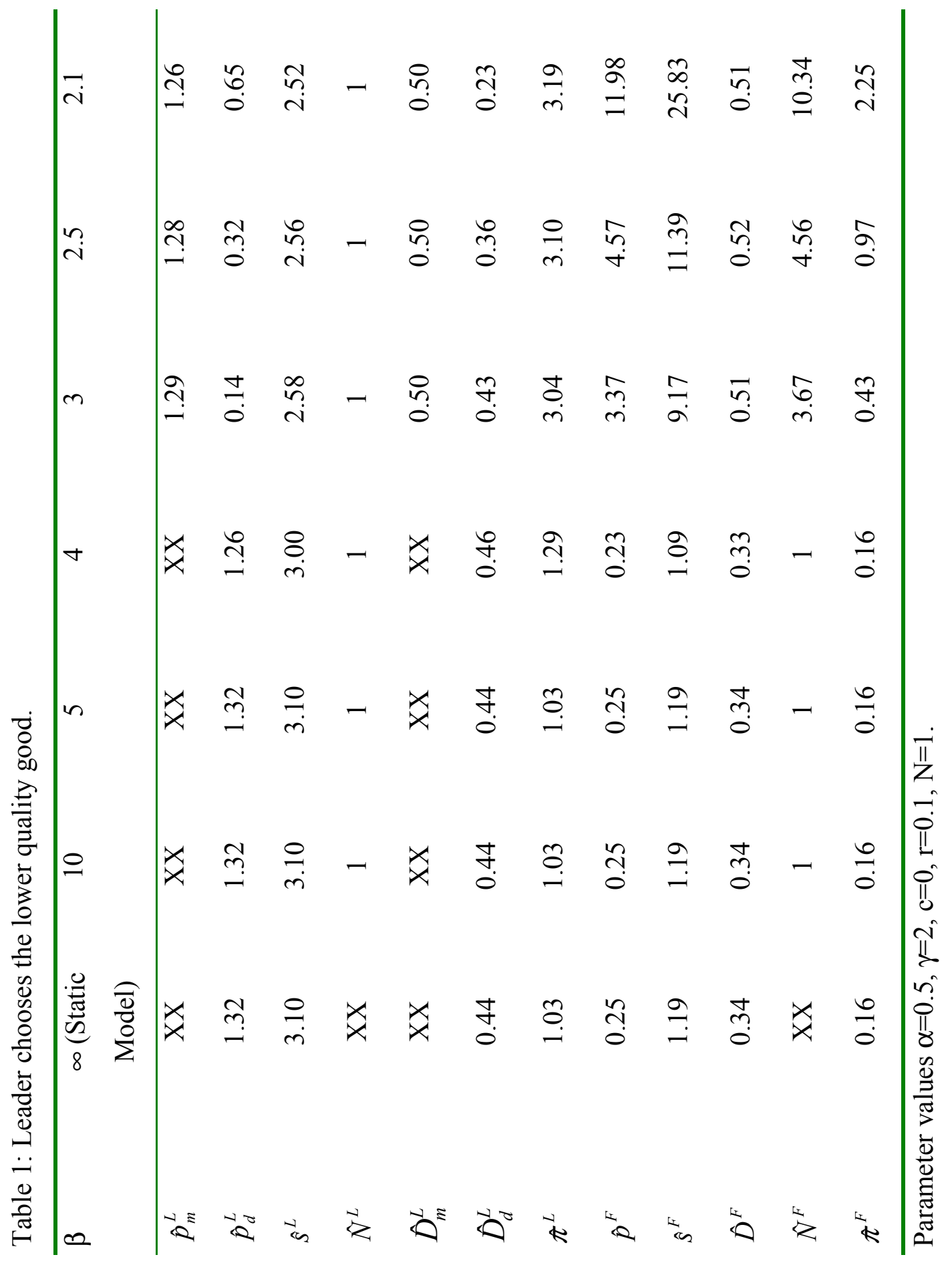

